\title{
Comparison of the Heating Values of Various Types of Fuel from Non-Wood Raw Materials
}

\author{
Zoilo González ${ }^{1}$, Manue I Javier Fe ria ${ }^{2}$, Fátima Vargas ${ }^{1}$, Ale jandro Rodríguez ${ }^{1, *}$ \\ ${ }^{1}$ Chemical En gineering Department, University of Córdoba, Spain \\ ${ }^{2}$ Chemical En gineering Department, University of Huelva, Spain
}

\begin{abstract}
The combustion of waste fractions fro $m$ the use of pruning of olive and orange trimmings used in the production of pulp for paper have been studied and the results were compared with those of other non-wood materials (Hesperaloe funifera, empty fru it bunches from oil palm, and banana trees), also used in the paper industry.

Heating values were compared with experimental values estimated with elemental analysis, contents of the main components (cellulose, lignin, extractives with ethanol-benzene) and proximate analysis (volatile, ash and fixed carbon). The best estimate of values were obtained with the equation that correlates the heating values and the amount of carbon fixed and volatile, which reproduces the experimental values with less than $4 \%$ errors

The values of flame temperature (between 1100 and $2400{ }^{\circ} \mathrm{C}$ depending on the excess air used and heat loss), dew point temperature (between 44 and $54^{\circ} \mathrm{C}$ ) and the air/fuel ratio (between 4.5 and $9.5 \mathrm{~kg}$ air $/ \mathrm{kg}$ fuel) were calculated.

Finally, the kJ prices obtained by combustion of the materials considered in this article were compared with those from fossil fuels and proved to be more expensive than the materials studied here (less than $3.4 € / \mathrm{MkJ}$ ) .
\end{abstract}

Keywords Fuel, Heating Values, Lignocellu losic Residues, Pulping

\section{Introduction}

From little more than one century ago, the use of wood for the production of cellulose pulp for papermaking has increased progressively, reaching levels of consumption of wood similar to the oil[1]. This has led to a wood supply problem, which worsens over time. For this reason, many of the investigations carried out in recent years have focused on finding new raw materials to avoid uncontrolled deforestation with serious ecological problems that occur in ecosystems. In this way the study of various materials has appeared such as agricultural, agro-industry and forest residues and alternative plants to those achieved in agri-food crops.

Since the 1970's, the pulp production of non-wood plant (non-conventional raw materials) has increased from approximately $7 \%$ to almost $12 \%$ of the total pulp produced, growing at 2-3 times greater than wood pulps [2-5].

The use of agricultural and agro-industry residues and alternative plants to food crops seems to be a good alternative to wood raw material, which can lead to excellent papers with special properties and can serve as the sole source of raw materials in some geographical areas.

Moreover, it is known that consumers are increasingly interested in having papers obtained by using clean technol-

\footnotetext{
* Corresponding author:

a.rodriguez@u co.es (Alejandro Rodríguez)

Published online at http://journal.sapub.org/ajee

Copyright (C) 2012 Scientific \& Academic Publishing. All Rights Reserved
}

ogies, or the fibers from recycled or non-wood plants; the use of agricultural and agro-industrial residues and non-wood plants could contribute to the preservation and maintenance of the environment, being able to reduce the large amount of wood used as feedstock in the production of paper pulp[1].

On the other hand, since paper consumption is parallel to a county's standard of living, which is rising throughout the world, it is expected that this increase, in a greater or lesser degree, will continue in the future.

The non-wood raw materials, compared to wood raw materials, have the particularity that contain fractions with little use for the production of pulp, such as those formed by leaves, bark, pith and young stems, which have relatively little cellulose content. However, these fractions, which can be called waste, should be processed along with the main fractions, rich in cellulose, to improve the economy of the pulping process. This is what is called biomass biorefinery, which uses all the components of the raw materials $[6,7]$.

The virtually unexploited potential of this residual biomass invites the development of procedures for its use as an energy source. The potential energy of lignocellulosic materials can be exploited by applying physical-chemical or biochemical procedures for conversion of their chemical energy into other simpler and more readily accessible types of energy $[8,9]$. The simplest physical-chemical procedure for exploitation of lignocellulosic materials is combustion. The biomass of forest and agricultural residues (felling, straw, canes, stalks, etc.) has been widely used as fuel that in turn is employed for the production of water vapor or elec- 
trical energy at small factories. Nowadays these waste materials are interesting as energy sources, using them in combustion processes[10-14].

Combustion is the oldest alternative to the energy exploitation of biomass. Its efficiency, like that of other thermal and physic-chemical methods, is markedly conditioned by the moisture content of the biomass, which can amount to $15-20 \%$ even in dry materials, The moisture content of biomass used for energy production should never exceed $60 \%$; otherwise, its heating value would be lower than that required to evaporate the moisture. The thermal yield of combustion is typically $20-22 \%$ for a $25 \%$ excess of air and biomass with a mo isture content of $50 \%$. Exceptional yields of up to $30 \%$ have also occasionally been reported $[15,16]$.

In this paper the heating values and cost of the heat unit obtained by combustion of various lignocellu losic residues with those of fossil fuels have been compared. Have also been proposed equations for the prediction of heating values of such residues from their composition. Finally, with the help of elemental analysis, the flame temperatures of the lignocellulosic residues have been calculated as well as the dew point temperature of the combustion gases and air/fuel ratio required.

\section{Experimental}

\subsection{An alytical Methods}

Chemical analysis were carried out according to the following procedures: moisture (Tappi T11m-59), cellulose (Tappi T9m 54), lignin (Tappi T13m-59), ethanol-benzene extractives (Tappi T6m-59), ash (Tappi T15m-58), volatile (UNE-32019); fixed carbon (difference between 100 and the sum of ashes plus volatiles). Elemental analysis was made using the Dumas method with a Eurovector "EA 3000" in the Spectroscopy Unit at the NIR / MIR Central Service for Research Support of the University of Cordoba.

\subsection{Heating Value}

The gross calorific values (constant volume) were determined according to "CEN/TS 14918:2005 (E) Solid biofuels-Method for the determination of the calorific value" and UNE 164001 EX standards by using a Parr 6200 Isoperibol Calorimeter

\subsection{Materials}

The following lignocellulosic materials have been investigated: residual fractions (mainly leaves and young stems) of orange and olive pruning (which have been called residual orange and residual olive), and three non-wood materials for the pulp industries: EFB (empty fru it bunches), Hesperaloe funifera and banana stalks

\section{Results and Discussion}

The results of the elemental analysis and the contents of cellu lose, lignin, ethanol-benzene extractable, ash, volatile and fixed carbon are presented in Tables 1 and 2.

Table 1. Elemental Analysis of Various Lignocellulosic Materials

\begin{tabular}{|c|c|c|c|c|}
\hline Material & Carbon, \% & Hydrogen, \% & Nitrogen, \% & Sulfur, \% \\
\hline $\begin{array}{c}\text { Orange Tree } \\
\text { Pruning }\end{array}$ & 45.46 & 6.15 & 0.41 & 0.01 \\
\hline $\begin{array}{c}\text { Residual Fraction } \\
\text { from Orange Tree } \\
\text { Pruning }\end{array}$ & 42.21 & 5.92 & 1.29 & 0.02 \\
\hline $\begin{array}{c}\text { Olive Tree } \\
\text { Pruning }\end{array}$ & 50.11 & 6.66 & 0.19 & 0.07 \\
\hline $\begin{array}{c}\text { Residual Fraction } \\
\text { from Olive Tree } \\
\text { Pruning }\end{array}$ & 44.18 & 6.25 & 0.51 & 0.03 \\
\hline $\begin{array}{c}\text { Hesperaloe } \\
\text { Funifera }\end{array}$ & 41.29 & 5.87 & 0.96 & 0.02 \\
\hline EFB & 45.52 & 6.04 & 0.44 & 0.04 \\
\hline Banana Tree & 39.67 & 5.65 & 1.44 & 0.05 \\
\hline
\end{tabular}

The carbon content is relatively close to each other and is very similar to those found in the literature $[15,16]$ for other lignocellulosic materials; wheat straw, sunflower stalks, vine shoots, cotton stalks and corn stalk stems. The lowest value for the case of banana trees and the highest for the olive pruning, whose wood proportion is higher, should be noted.

In relation to the hydrogen content can be indicated the same that in the case of the carbon content, also being the lowest value for the case of the banana and the highest in olive pruning

The nitrogen content is low and differs more from one material to another, as observed in the residual fractions which have higher values such as in the banana tree and Hesperaloe funifera, which are less woody.

The sulphur percentages are very low, so the fuel gases of these lignocellu losic materials were poor in $\mathrm{SO}_{2}$, compared to gases from the combustion of fossil fuels.

Table 2. Contents of Cellulose (Ce), Lignin (L), Extractable (E), Ash (A), Volatile (V) and Fixed Carbon (Cf) of Various Lignocellulosic Materials

\begin{tabular}{|c|c|c|c|c|c|c|}
\hline Material & $\mathrm{Ce}, \%$ & $\mathrm{~L}, \%$ & $\mathrm{E}, \%$ & $\mathrm{~A}, \%$ & $\mathrm{~V}, \%$ & $\mathrm{Cf}, \%$ \\
\hline $\begin{array}{c}\text { Orange Tree } \\
\text { Pruning }\end{array}$ & 73.20 & 19.95 & 3.57 & 3.37 & 78.79 & 17.84 \\
\hline $\begin{array}{c}\text { Residual } \\
\text { Fraction } \\
\text { from Orange } \\
\text { TreePruning }\end{array}$ & 63.39 & 14.78 & 6.49 & 14.84 & 78.30 & 6.86 \\
\hline $\begin{array}{c}\text { Olive Tree } \\
\text { Pruning }\end{array}$ & 69.23 & 19.51 & 9.00 & 1.18 & 79.91 & 18.91 \\
\hline $\begin{array}{c}\text { Residual } \\
\text { Fraction } \\
\text { from Olive } \\
\text { TreePruning }\end{array}$ & 66.11 & 17.53 & 12.49 & 3.59 & 81.42 & 14.99 \\
\hline $\begin{array}{c}\text { Hesperaloe } \\
\text { Funifera }\end{array}$ & 78.11 & 9.88 & 5.18 & 5.90 & 80.78 & 13.32 \\
\hline EFB & 75.60 & 17.17 & 3.87 & 3.45 & 74.81 & 21.74 \\
\hline Banana Tree & 55.48 & 22.25 & 7.59 & 15.35 & 70.14 & 14.51 \\
\hline
\end{tabular}

The cellulose content varies from $55 \%$ to the banana tree to $78 \%$ for $H$. funifera, and the lignin content varies from $10 \%$ H. funifera to $22 \%$ for the banana tree. Similar results were found for other lignocellu losic materials: wheat straw, 
sunflower stalks, vine shoots and cotton stalks[16].

The extracts values are very high for olive tree prunings and their residual fraction compared to other tested materials, which are in the order of other lignocellulosic materials such as wheat straw, sunflower stalks, vine shoots and cotton stalks[16].

The ashes values are abundant in the residual fraction of orange pruning and banana tree, and plenty for other materials tested, with respect to the pruning of olive trees, which are in the order of hardwoods and softwoods $[15,16]$.

Volatile chemicals are high (78-80\%), except for the EFB and banana tree, which are relatively low compared with other lignocellulosic materials: wheat straw, sunflower stalks, vine shoots and cotton stalks[16].

Finally, the fixed carbon is very high for EFB and very low for residual fraction from orange pruning, being intermediate for other materials and those found in the literature (16).

Table 3 presents the experiment results of the heating values of lignocellulosic materials tested.

In the literature $[17,18]$ found equations that predict the heating value, $\mathrm{HV}(\mathrm{kJ} / \mathrm{kg})$ :

$$
\begin{gathered}
\mathrm{HV}=393.81 \mathrm{C}+230.22 \\
\mathrm{HV}=436.66 \mathrm{C}-305.51 \\
\mathrm{HV}=173.89 \mathrm{Ce}+266.29 \mathrm{~L}+321.87 \mathrm{E} \\
\mathrm{HV}=173.89 \mathrm{Ce}+266.29\left(100-\mathrm{Ce}^{\prime}\right)
\end{gathered}
$$

$\mathrm{HV}=(1-\mathrm{A} /(\mathrm{Ce}+\mathrm{L}+\mathrm{E}))(173.89 \mathrm{Ce}+266.29 \mathrm{~L}+321.87 \mathrm{E})(5)$ where $\mathrm{C}$ is the total carbon content (\%), Ce, L, E and $\mathrm{A}$ the contents of cellulose, lignin, extractives and ash (all in\%), and $\mathrm{Ce}^{\prime}$ the cellulose content on an extractable-free basis (\%).

By apply ing of the experimental data showed in Tables 1 and 2 in the equations (1) to (5), the heating values presented in Table 3 were obtained, which also shows the values of the errors in the estimates for the experimental heating values.

As it can be seen, equation (3) is the best at reproducing the heating values of the test materials (errors less than $8 \%$ in the worst case for the residual olive pruning). Equation (1) reproduces the heating values with errors less than $7 \%$, with the exception of the banana tree that reproduces an error close to $11 \%$. Equation (2) reproduces the heating values with errors less than $7 \%$, with the exception of olive pruning which reproduces with an error of almost $13 \%$. Equations (4) and (5) reproduce good heating values of lignocellulosic materials, except those containing high values of ashes: residual orange tree and banana tree.

By correlating the experimental data (heating values against the sum of volatiles (V) and fixed carbon (Cf) contents) it is possible to obtain:

$$
\mathrm{HV}=123.61 \mathrm{~T}+6746.05
$$

where $\mathrm{T}$ is the sum of the volatiles and fixed carbon contents. This equation reproduces the heating values of all materials tested with errors less than $4 \%$.

In the literature there is a similar equation for agricultural residues (16):

$$
\mathrm{HV}=339.82 \mathrm{~T}-14814.93
$$

The heating values of the materials tested here, are re- produced with small errors, except for materials with a high ash content, having the equation (7) the same defects as equations (4) and (5).

Jiménez et al [15] also proposed a similar equation for the case of agricultural residues, food industry waste and forest residues from eucalyptus and holm:

$$
\mathrm{HV}=313.30 \mathrm{~T}-10814.08
$$

The above equation reproduced properly the heating values of the materials considered, apart from the banana tree which has a $12 \%$ error.

Using the elemental analysis of materials considered (Table 1) and following the estimation techniques described in the literature $[19,20]$ determines the values of flame temperature, dew point and air/fuel ratio, presented in Figures 1 to 9 .

The high values of flame temperature demonstrate the possibility of using these materials in the production of steam.

The dew po int of all materials tested is low for co mbustion gases, thus avoiding condensation in chimneys and flue pipes, preventing corrosion that could cause the condensation; anyway, in the event of such condensation, the phenomenon would not be very serious given the small sulphur content of the material considered. This is an additional advantage that makes these fuels clean.

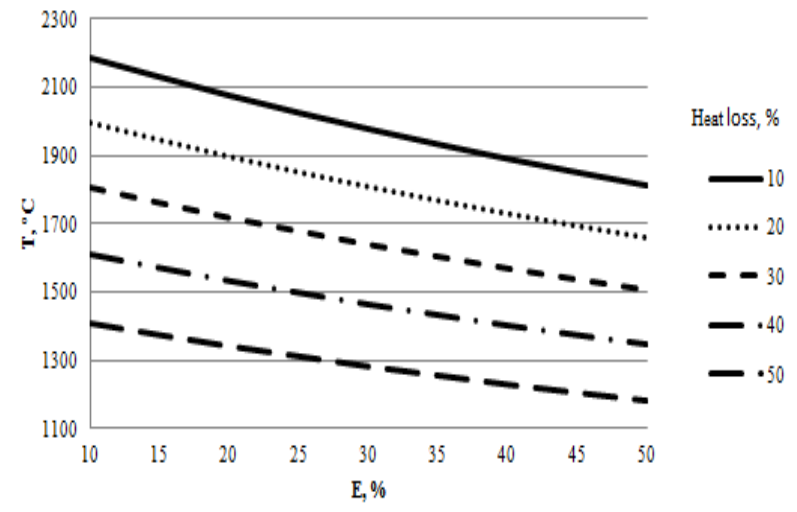

Figure 1. Flame Temperature for the Orange Tree Pruning

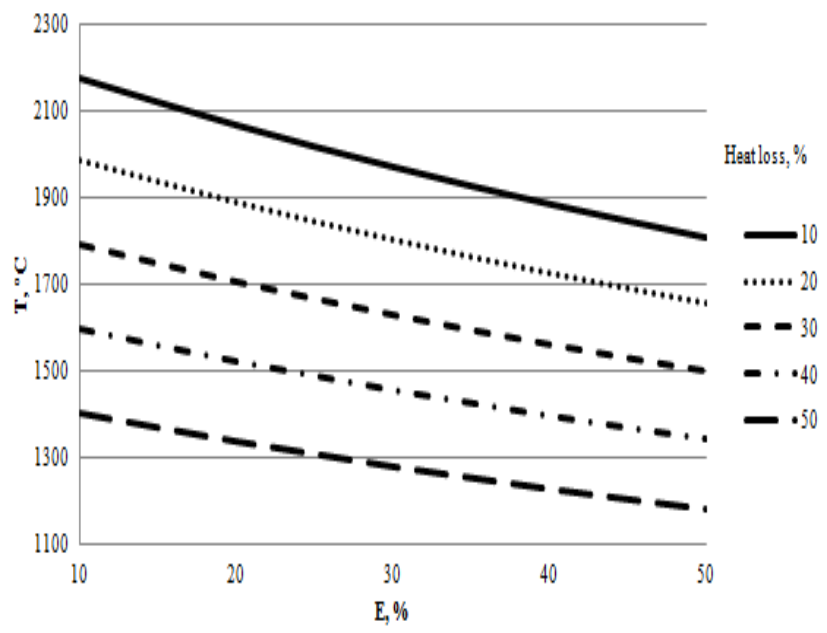

Figure 2. Flame Temperature for the Residual Fraction from Orange Tree Pruning 


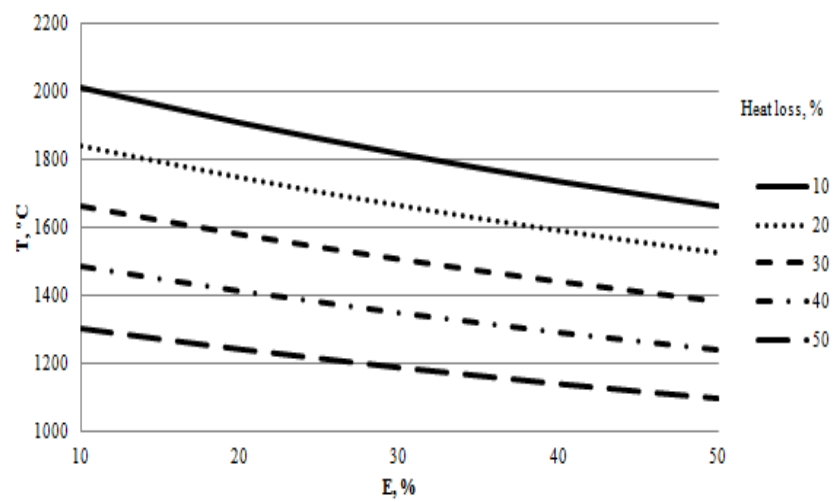

Figure 3. Flame Temperature for the OliveTree Pruning

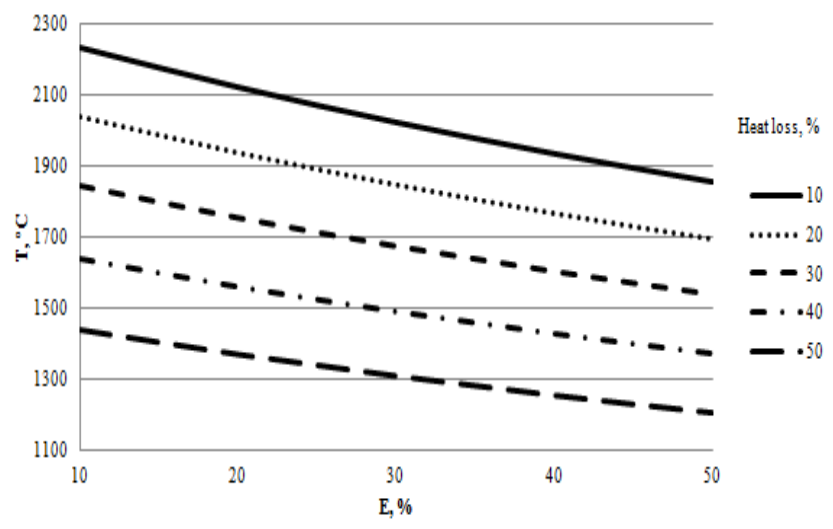

Figure 4. Flame Temperature for the Residual Fraction from Olive Tree Pruning

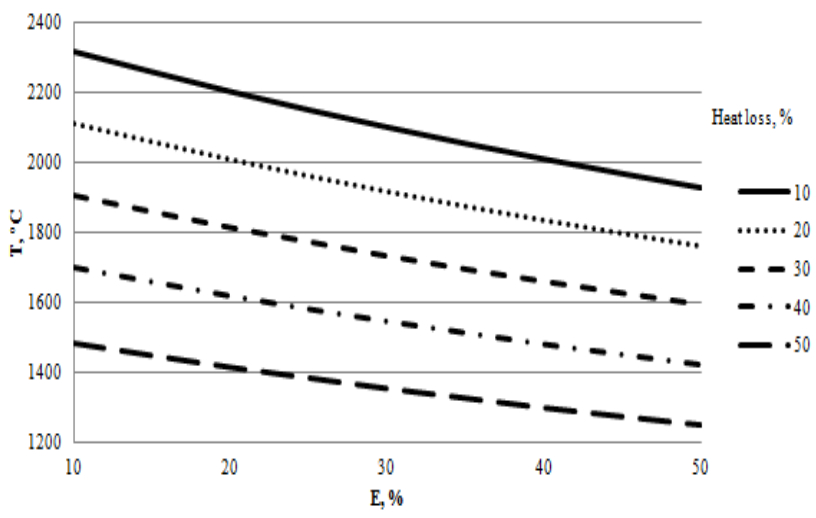

Figure 5. Flame Temperat ure for the Hesperaloe Funifera

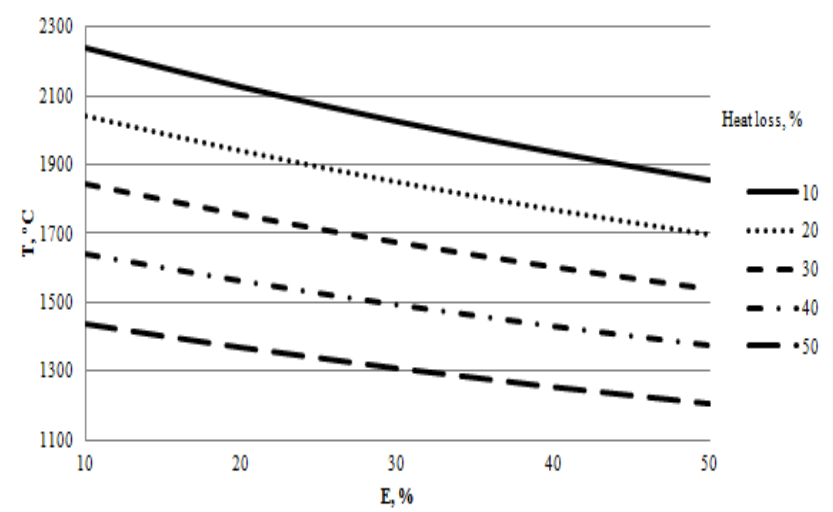

Figure 6. Flame Temperature for the Empty Fruit Bunches of Oil-Palm

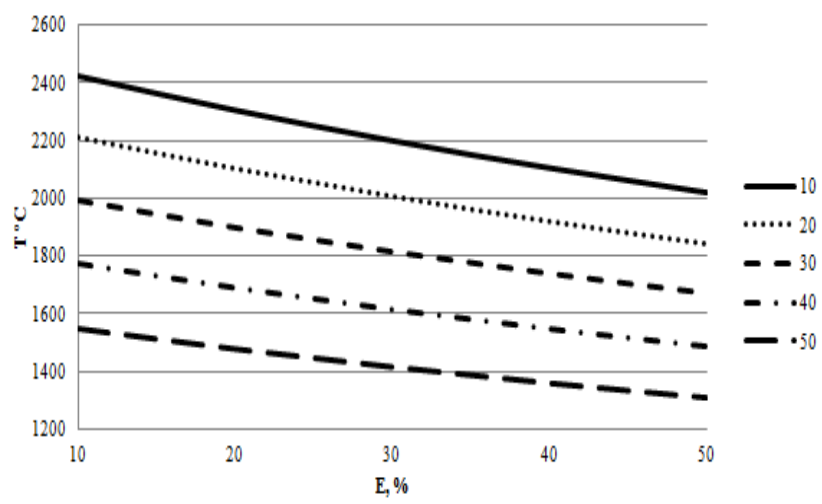

Figure 7. Flame Temperature for the Banana Tree

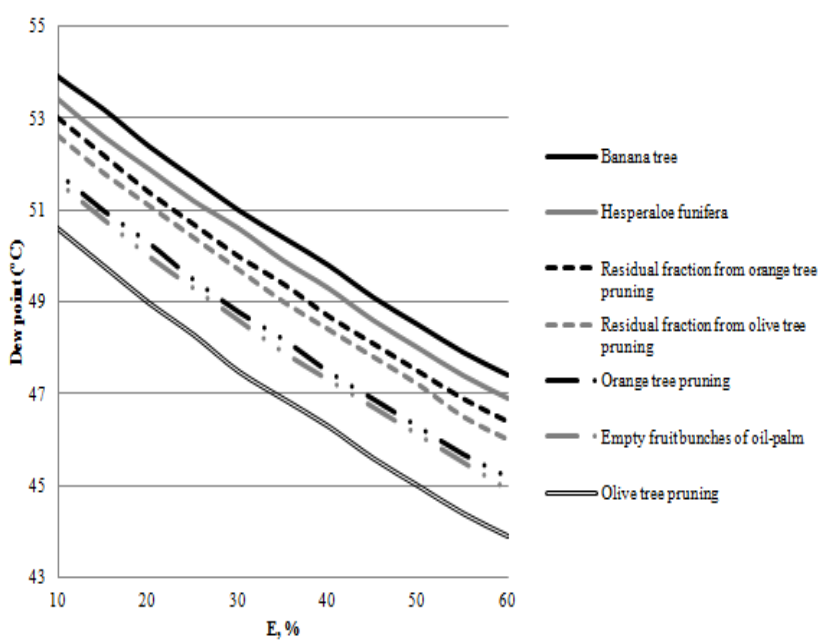

Figure 8. Dew Point Temperature of Flue Gas as a Function of Excess Air Used for Different Lignocellulosic Materials

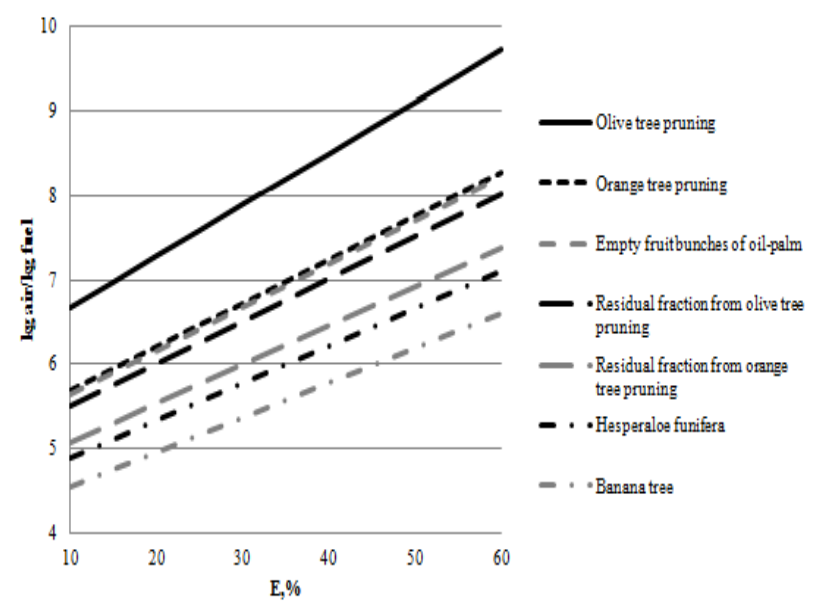

Figure 9. Air/Fuel Ratio as a Function of Excess Air Used in the Combustion of Different Lignocellulosic Materials

Table 4 compares the heating values, unit cost of the fuel and cost of the heat units obtained by combustion of the different types of fuel.

The cost of the various ligmocellulosic residues considered here are different. Thus, residual fractions from orange tree pruning and olive tree pruning, and empty fru it bunches from oil palm are the cheapest, since they only have to consider the costs of upgrading the energy plant (they are 
paper industry waste (residual fractions from pruning)) or agrofood (EFB), and other costs not required for other lignocellulosic residues, such as data collection in the fields and their transport to the combustion plant.

Table 4. Comparison of the heating values and the cost of the energy obtained from various types of fuel

\begin{tabular}{|c|c|c|c|}
\hline \multirow{2}{*}{ Fuel } & $\begin{array}{c}\text { Heating } \\
\text { Values }\end{array}$ & Cost of Fuel & $\begin{array}{c}\text { Cost of Heat } \\
\text { unit }\end{array}$ \\
\cline { 2 - 4 } & MkJ/t & $€ / \mathrm{t}$ & $€ / \mathrm{MkJ}$ \\
\hline Orange TreePruning & 18626 & 60 & 3.22 \\
\hline $\begin{array}{c}\text { Residual Fraction } \\
\text { from Orange TreePruning }\end{array}$ & 16870 & 30 & 1.79 \\
\hline Olive Tree Pruning & 19110 & 60 & 3.14 \\
\hline $\begin{array}{c}\text { Residual Fraction } \\
\text { from Olive Tree Pruning }\end{array}$ & 18699 & 30 & 1.60 \\
\hline Hesperaloe Funifera & 17757 & 60 & 3.38 \\
\hline EFB & 19045 & 30 & 1.58 \\
\hline Banana Tree & 17751 & 60 & 3.38 \\
\hline Mineral Coal & 25943 & 110 & 4.24 \\
\hline Heating Fuel & 37665 & 800 & 21.24 \\
\hline CommercialPropane & 43888 & 1650 & 37.60 \\
\hline
\end{tabular}

As can be seen in table 4, the MkJ of energy obtained by combustion of industrial waste is cheaper than that obtained from the agricu ltural residues (olive tree and orange tree and banana tree pruning), which in turn is cheaper than the one obtained from mineral coal and even much cheaper than the one obtained from fossil fuel fluids. Moreover, we should emphasize some of the advantages of the lignocellulosic residues studies: they are renewable and release very small amounts of sulfur dioxide in combustion gases and smaller amounts ofash than the solid fossil fuel, so, at the worst, they are good competitors with fossil fuels.

\section{Conclusions}

The values of residual heating fractions from olive tree and orange tree pruning have been determined and compared with those of other non-wood materials (Hesperaloe funifera, empty fruit bunches from oil-palm and banana tree), also used in the paper industry.

Heating values are compared with experimental values estimated with elemental analysis, contents of the main components (cellulose, lignin, extractives with ethanol-benzene) and proximate analys is (volatile, ash and fixed carbon). The best estimates are obtained with the resulting equation to correlate the heating values and the amount of volatile and fixed carbon, which reproduces the experimental values with errors less than $4 \%$.

The values of flame temperature (between 1100 and $2400{ }^{\circ} \mathrm{C}$ depending on the excess air used and heat loss ) have been calculated, indicating that these lignocellulosic materials are suitable for the production of steam. The dew point temperature of flue gas ( 44 to $54{ }^{\circ} \mathrm{C}$ ) has also been given, which when low prevents condensation of water vapor in chimneys and other potentially corrosive systems. It has been found that the air/fuel ratio is between 4.5 and $9.5 \mathrm{~kg}$ air/kg fuel, depending on the excess air used.

After comparing prices, the MkJ obtained by combustion of the materials considered here compared with those from fossil fuels, the cost of the materials studied here were much cheaper (less than $3.4 € / \mathrm{M} \mathrm{kJ}$ ) .

\section{ACKNOWLEDGEMENTS}

The authors are grateful to Ecopapel, S.L. (Écija, Sevilla, Spain) for their support, and to Spain's DGICyT and Junta of Andalucía for funding this research within the framework of the Projects CTQ2010-19844-C02-01 and TEP-6261.

\section{REFERENCES}

[1] Jiménez L. Pastas celulós icas de materias primas alternativas a las conven cionales. 2005. Editorial Gráficas Sol. Sevilla.

[2] Patel RJ, Angadiyavar CS and Srinivasa Y. Nonwood fiber plants for paper making. A review. Nonwood Plant Fiber Pulping 1985; 15; 77-90.

[3] Atchinson JE. Twenty-five years of global progress in nonwood plant fiber repunping. Tappi J 1996; 79 10; 87-97.

[4] Simula M. Fibre supply: The achilles hell of the global pulp and paper industry. Paperi Ja Puu-Paper and Timber 2002; 84 $1 ; 16$.

[5] Alaejos J, López F and Eugenio ME. Using of non-wood raw materials for cellulose pulp. Review. Afinidad 2004; 61 513; 400-410.

[6] Towers M, Browne T, Kerekes R, Paris J and Tran H. Biorefinery opportunities for the Canadian pulp and paper industry. Pulp Pap-Canada. 2007108 6; 26-29.

[7] Kelley SS. Lignocellulosic biorefineries: reality, hype, or something in between?. ACS Syposium Series. 2007; 954; 31-47.

[8] Rodríguez A, Rosal A and Jiménez L. Biorefinery of agricultural residues by fractionation of their components through hydrothermal and organosolv processes. Afinidad 2010;67 $545 ; 14-19$

[9] Jiménez, L and Rodríguez A. Valorization of agricultural residues by fractionation of their components. The Open Agriculture Journal 2010; 4; 125-134.

[10] Nieblas R, Rubio A, Mendoza V, and Bladimir H. Charaterization of sugarcane wastes as fuel. Centro Azúcar 1990; 17 $3 ; 16-20$

[11] Rey FJ, Martín J, Villamanan MA and San José J. Thermal analysis of agricultural residues with application to production of fuels. Journal of Thermal Analysis 1993; 40 1; 239-247.

[12] Arvelakis S and Koukios EG. Physicochemical up grading of agroresidues as feedstocks for energy production via thermochemical conversion methods. Biomass Bionerg 2002; 22 5; 331-348. 
[13] Ozturk HH and Bascetinlik A. Energy, exploitation of agricultural biomass potential in Turkey. Energy Exploration and Exploitation 2006; 24 4; 313-330.

[14] Overend RP and Wright LL. Biomass energy. Energy conversion 2008; 3 1/3; 18.

[15] Jiménez L and González F. Study of the physical and chemical properties of lignocellulosic residues with a view to the production of fuels. Fuel 1991; 70 8; 947-950.

[16] Jiménez L, Bonilla JL and González F. Physical and chemical characterization of agricultural wastes. Afinidad 1991; 48431 ;
39-44.

[17] Shafizadeh F and Degroot WG. Thermal uses and properties of carbohydrates and lignius. Academic Press. 1976 New York.

[18] Tillman DA. Wood as an energy recourse. Academic Press. 1978 New York.

[19] Reynolds WC and Perkins HC. Ingeniería Termodinámica. 1980 McGraw-Hill. Mexico.

[20] Segura S. Termodinámica Técnica.1980 Ed. AC. Madrid 